\title{
EN CASA DE JAVIER HERAUD
}

\author{
Fredy Gambetta Uría ${ }^{1}$
}

La casa del poeta, donde viven sus padres, solos en amplia morada, hoy que los hijos crecieron y se fueron a caminar por los senderos de la vida y de la muerte, se encuentra ubicada en la calle San Martín 639, del cada vez menos romántico distrito de Miraflores, en la capital del Perú.

Llego a la familia Heraud-Pérez acompañado del Dr. Jorge Heraud, el mayor de los hermanos, que guarda un extraordinario parecido con el gran ausente.

Es a su hermano Jorge (Coco) a quien dedica el primer ejemplar de EL RÍO apenas aparecido en los artesanales talleres de la Rama Florida. En la dedicatoria, conservada con amoroso celo, Javier hace alusión a los cuentos que de niño le contaba su hermano para que sus sueños le fueran aún más dulces, revestidos por la imaginación del poeta que en el nacía. Pero también, en esa dedicatoria, que anonadado contemplo, sostenida en mis manos, el negro presagio de la muerte atraviesa las líneas de letras separadas. "Con el recuerdo del muerto de la familia" certifica, una vez más, lo que los antiguos pensaban respecto a las virtudes proféticas que acompañan a los poetas.

En la sala principal de la casa soy presentado a la señora Victoria Pérez Telleria de Heraud, la madre ("No sabes cuánto agradezco ser hijo tuyo" -carta fechada en la Habana el 13.mayo.62) y a don Jorge Heraud Cricet, el padre ("Yo siento que cada día me parezco más a ti" -carta fechada en la Habana el 16.mayo.62)

Ambos son de mediana estatura. Doña Victoria tiene una expresión de dulzura y de tristeza. El fino rostro, que es ganado por el tiempo, lo enmarca una cabellera ondulada y cana. Durante la conversación tendrá momentos de gran excitación cuando habla de la infancia de sus hijos y también silencios, aunque no prolongados, impresionantes, en los que baja la mirada, agacha la cabeza y entrecruza las delgadas manos.

Don Jorge Heraud Cricet mantiene un aire jovial durante la entrevista. Disimula su calvicie con una gorrita de jockey. Sus ojos son pequeños, claros y vivaces. En el corto tiempo que durará la conversación, por las ocupaciones de su hijo Jorge, trata de contar el máximo de sus recuerdos. Adivino en él un secreto orgullo de haber entregado al patrimonio cultural de la patria un hijo tan célebre. Ambos tienen muy claro que ningún homenaje logrará que la muerte les devuelva al hijo amado.

La persona que visite la casa de los Heraud y transponga el umbral lo primero que verá, sobre la chimenea de la sala, será un cuadro con un retrato de Javier que fuera pintado en base a una de sus fotografías más difundidas. Sobre la mesa de centro se luce la fotografía, que le tomaron en un aula de la universidad Católica, en 1960, y que sirvió de modelo al pintor." En ese cuadro esta exacta la mirada de mi hijo" nos dice la señora Victoria.

Después, recorriendo los ambientes del hogar, por gentil invitación del dueño de casa, apreciaría, donde mi vista reparara, recuerdos del poeta. "Tengo sus fotogra-

${ }^{1}$ Poeta y Cronista de Tacna. El texto que publicamos testimonia una visita que el autor hiciera a los padres del poeta Javier Heraud, en la primavera de 1981. 
fías hasta en la cocina" -nos confidencia la amorosa madre. "Mis hijas pensaban que me iba a volver loca con esos recuerdos. Pero ya ve usted, han pasado 18 años y esas fotografías son mi único consuelo, lo único que me brinda cierta resignación".

Entre los artistas son los poetas los que con mayor sentimiento evocan la casa que habitaron en la infancia. Es a veces una casa la que despierta en el alma de los hombres el sueño de un poeta dormido.

Javier Heraud escribió dos hermosos poemas: MI CASA MUERTA y CANCION DE MI CASA MUERTA. Sin embargo, la residencia familiar no fue destruida íntegramente, "Ampliamos solamente la parte delantera y se destruyó parte del jardín" -anota el padre del poeta. "Pero conservamos el manzano y el membrillo tan queridos por Javier. No he permitido que nadie los toque jamás" -nos cuenta la señora Victoria.

No derrumben mi vieja casa,

había dicho,

dejen al menos mis granadas

y mis moras,

mis manzanas y mis

rejas.

(MI CASA MUERTA - fragmento)

Cuando levantaban las columnas, de lo que sería la actual sala, Jorge y Javier encerraron, en medio de ellas, en frascos de mermelada, poemas, predicciones para el futuro, monedas de la época y otros pequeños recuerdos. Igual cosa hicieron en algunas de las esquinas, entre las bases.

Hoy, según nos dice don Jorge, la casa es muy grande para los esposos. El bullicio de los chicos ha pasado, el silencio habita la morada. Piensan vender la propiedad. Aun siendo un proyecto, la madre está preocupada desde ahora, con toda razón, porque no le vayan a destruir aquellos recuerdos que dejaron sus hijos -entre las columnas y las bases.

Mi conversación con los padres y el hermano de Javier es desordenada, no ha sido planeada para una entrevista, ni para hurgar intimidades. "Vea usted, recuerda don Jorge, a esta casa vino Pedro Beltrán para el pésame por la muerte de mi hijo. Y fue en la esquina de la sala donde Jorge, todavía un mozo, se enfrentó al Director de La Prensa para decirle que hacía daño con las noticias malintencionadas que propalaba. Beltrán, con toda su experiencia, quedó anonadado. Después de ello, y de mi carta al periódico, no más se ocuparon despectivamente de la acción en la que pereciera mi hijo".

"Por otro lado debo contarlo -me dice el padre del poeta -que hace poco mi amigo el General Callo, ya retirado estuvo en una reunión a la que asistía el doctor José Luis Bustamante y Rivero. Allí le escuchó decir al Dr. Bustamante que él tenía como libro de cabecera las Obras Completas de Javier y que releía el epistolario por considerar perfecto el estilo del poeta en ese difícil género".

Luego de tomar un café me invitan a subir a ver el cuarto de Javier. La escalera, de fina madera, tiene sus escalones no muy anchos. "A Javier no le cabían los pies en 
los peldaños -nos cuenta la madre. Los bajaba de tres en tres, sobre todo en las mañanas cuando apurado venia al comedor para desayunar. Estuve escuchando el ruido de sus saltos en la escalera hasta hace muy poco".

En el segundo piso se ubican la biblioteca y los dormitorios. "El cuarto de fondo era el de Gustavo, mi hijo menor -dice la señora Victoria. Cuando el chico no quería subir a dormir pronto sus hermanos dejaban que duerma abajo y lo subían por la escalera agarrándolo uno de la cabeza y el otro de los pies. Jorge y Javier hicieron esa operación innumerables veces".

Gustavo, el hijo menor, hoy se encuentra en el extranjero. Leyendo las cartas de Javier apreciamos el inmenso amor que le tenía al benjamín de la familia expresado, además, en un poema de intenso amor fraternal.

\section{a Gustavo}

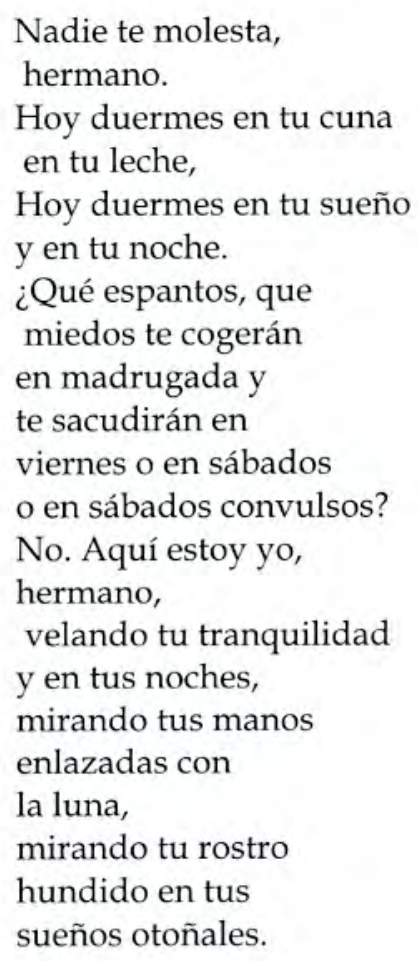

En la biblioteca de la casa hicieron las tareas escolares todos los hermanos. Tiene un escritorio en el centro y luce varios estantes de madera. Aquí no podía faltar la presencia "del muerto de la familia". Veo dos ceniceros de yeso con manchas de nicotina, recuerdo de cigarros fumados por el poeta, mas allá un dibujo que le hiciera Pancho Izquierdo y las varias ediciones, en idiomas extranjeros, de los versos tan queridos.

Yo le había confesado al Dr. Jorge Heraud que mi libro de la primera edición, 
de las obras completas y homenaje a su hermano me fue sustraído. Entonces se acerca a un anaquel y toma uno de los dos ejemplares que conserva la familia, con el ánimo de obsequiármelo. Digo que no, que no lo acepto. Esos son recuerdos invalorables. "Tiene usted razón -asiente la madre-Mis nietos se desviven por los recuerdos de su tío. Varias veces vienen contentos para decirme que en el colegio han hablado de Javier".

Al salir de la biblioteca llego al cuarto del poeta. Ya no se conserva intacto como lo apreciábamos en la fotografía de aquella primera edición. Esta la ventana, junto a la cual se ubicaba el escritorio, un closet con paneles adornando con las figuras que el mismo Javier pegara y su letra, escrita con tiza blanca. Leo la frase que el tiempova borrando: ¿Qué es esto? ¡Oh!"

Doña Victoria y su hijo se acercan a la ventana preguntándose: “¿Estará el zapato todavía?". Se trata de un zapato viejo que Javier lanzo por la ventana, sobre un tejado vecino, y que nadie lo había movido hasta los primeros meses de este año de 1981.

El cuarto no se conserva intacto porque cuando se recibió la visita de una las hermanas de Javier, con sus menores hijos, lo habilitaron como albergue.

Veo también el primer cuarto donde, de niños, dormían juntos Jorge y Javier. Es el cuarto en el que apenas cabían las dos camas de los pequeños y en el que el hermano mayor contaba las historias que recordaba el poeta. Ese cuarto mantiene su "alta ventana mañanera".

Camino emocionado en esta casa tan querida donde habitara este poeta símbolo de mi generación, ejemplo del ideal juvenil. Para mí, que seguí desde la adolescencia los pasos de Javier, leí su poesía, sus cartas, los homenajes de los amigos, conocí la iconografía que se difundía, esta visita es un sueño, la plasmación de un antiguo anhelo.

Nuevamente en el primer piso, me invitan a escuchar una cinta que conserva la entrevista que el escritor Mario Vargas Llosa le hiciera a Javier, por Radio Difusión Francesa en Paris, en setiembre de 1962. Es la conversación entre dos jóvenes escritores que hicieran que inician sus carreras literarias. Mientras se hacen los preparativos, para colocar la cinta en una antigua grabadora de carrete grande, la madre ha pedido permiso y abandona la habitación. Para ella escuchar la voz de su hijo muerto constituye un dolor muy grande.

La cinta tiene 19 años exactos y ya se aprecia el paso del tiempo. Escuchamos la presentación y las preguntas de Vargas Llosa al joven poeta peruano, ganador del premio "EL POETA JOVEN DEL PERU", otorgado por Cuadernos Trimestrales de Poesía, revista editada en Trujillo, 1960.

En las respuestas Javier Heraud confiesa su intención de escribir una poesía descriptiva, clara, que sea dirigida a la comprensión de la mayoría. Afirma que la poesía peruana atraviesa por uno de sus mejores momentos y cita a Romualdo, Belli, Sologuren y Rose. Habla de sus preferencias en poesía: "Vallejo, Neruda, Machado, Hernández y Dylan Thomas".

Termina la breve entrevista con la lectura, precisamente, del poema MI CASA MUERTA. Heraud leía pausadamente, vocalizando bien las palabras.

Leyendo las cartas de Javier encontramos varias veces el misterioso nombre de Degale. Dégale era el sobrenombre del más íntimo de los amigos del joven Heraud. Se llama Deyenhart Briegleb y vivía a pocos metros de la casa. Fueron juntos a la 
escuela, hicieron mataperradas y seguramente compartieron amoríos con las bellas miraflorinas. Cuando Javier estuvo en Paris, y ya le era imposible quedarse más días, escribió una carta a Degale, que estaba en Europa, me parece que en Austria. El fiel amigo le dice que no se mueva de la Ciudad Luz, que le está remitiendo un sobre con dinero, directamente a la Embajada del Perú, y que lo esperase para pasarla bien en la capital de Francia.

Javier Heraud iba diariamente a buscar la carta y nunca se la entregaron. Años más tarde, nos cuenta la madre del poeta, se realizaba la fiesta en una Embajada peruana. A ella asistía Briegleb. Todos estaban con una copa de champagne en la mano. De pronto, un amigo le cuenta a Degale la triste noticia de la muerte de Javier. El amigo íntimo estrello la copa en el piso y abandonó sollozando aquella reunión.

En Miraflores, años más tarde, la familia Heraud recibió la visita de Degale que no dejaba de llorar ante tan injusta verdad.

Mi visita ha terminado. Es casi el mediodía, de un viernes de invierno. Los padres me invitan a visitarlos cuando regrese a Lima.

Al salir, frente al jardín, a pocos metros del membrillo y del lugar donde estuviera la enredadera ("La enredadera era un caballo") emocionado beso la mejilla de la madre que tantas veces los labios de Javier Heraud besaran.

Tacna, setiembre de 1981. 